\title{
RECLAMATION OF USED PETROLEUM LUBRICATING OILS.
}

\author{
By Winslow $\mathrm{H}$. Herschel and A. H. Anderson.
}

ABSTRACT.

Used lubricating oils may be reclaimed by apparatus already commercially available and thus saved for further use. Such reclaimed oils will pass all the commonly accepted tests for new oils, such as flash point, viscosity, and sediment. It is more doubtful whether the reclamation process sufficiently reduces the organic acidity and sulphur content, but there is some doubt whether this is necessary. There is little possibility that the organic acidity would ever be high enough in an uncompounded oil to cause corrosion. It is often the case that high acidity is accompanied by readiness of emulsification, but exceptions have been found, so that the value of the test for acidity must lie in the possibility that an oil of high acidity will not prove durable in use. When more is known concerning the best test for durability of an oil, it may be necessary to modify reclaiming methods, so that reclaimed oils may meet such test.

CONTENTS.

I. Introduction.........................

II. The deterioration of lubricating oils in use .................... 94

III. Present methods of reclaiming used oils...................... 95

IV. Tests with motor-oil purifier.............................. $9^{8}$

V. Organic acidity $\ldots \ldots \ldots \ldots \ldots \ldots \ldots \ldots \ldots \ldots \ldots \ldots \ldots \ldots \ldots \ldots \ldots \ldots \ldots$ ro

VI. Interfacial tension................................ ro2

VII. Refining processes..................................... I04

VIII. The cause of sludge formation............................ ro6

IX. Conclusions.................................... ro 8

\section{INTRODUCTION.}

There is an increasing demand for petroleum products for fuel and lubricants due to the increasing use of internal-combustion engines in the Navy, merchant marine, the omnipresent automobile, and elsewhere. The supply of crude oil from the petroleum fields of the United States can not be increased with the same rapidity, and it is already necessary to import crude oil from Mexico in large and increasing amounts. The petroleum reserves have been thoroughly investigated by the Geological Survey, and it is found that "a big fraction of the domestic petroleum is gone. Whether that fraction is one-third, as present 
knowledge indicates, or is one-fourth or even one-fifth makes no difference in the consideration demanded by the situation." 1

In the western part of the United States there is an abundance of oil shale, but the processes of extracting and refining the oil are still in the experimental state, and shale oil must be regarded as a product of the future rather than as a means already available for supplementing the petroleum from the wells.

Oil used as fuel is lost past recovery, but much of the lubricating oil which has been used and discarded as unfit for further service can be reclaimed. Automobile oils especially deteriorate rapidly in use, but the used oil may be restored to its original condition by processes already applied on a commercial scale in several cities. Thus, the reclamation of used oils furnishes a method, already available, of aiding in the conservation of an irreplaceable natural resource.

\section{THE DETERIORATION OF LUBRICATING OILS IN USE.}

It has become recognized as good practice, especially for highspeed machinery, to use a forced-feed lubricating system, the oil being pumped from a settling tank through the bearings and allowed to flow back to the tank. The oil is thus used over and over again, and under these conditions it gradually oxidizes and grows more viscous and may eventually form a deposit known as sludge.

There are additional causes of deterioration of oils which are used in internal-combustion engines, as in automobiles. The oil in the crank case is usally diluted by kerosene (the "heavy ends" or unvolatilized fraction of the gasoline) which tends to make the oil decrease in viscosity with use. On account of this crank-case dilution it is not always easy to distinguish between troubles due to the oil and those due to the fuel. When there is corrosion in the crank case, there is at least as much probability that it is due to sulphur in the fuel as to any property of the oil when new. There is also a possibility of dilution by a volatile product of "cracked" oil, ${ }^{2}$ but the amount of this material may be assumed negligible in comparison with the heavy ends of the fuel. The conditions of use in an automobile cylinder are very severe, the oil film being exposed to great heat which burns away part of the oil, leaving so-called carbon deposits which

\footnotetext{
1 C. G. Gilbert and J. E. Pogue, Smithsonian Institution Bull. 102, 1, p. 55; I9I9.

2 While cracking is here undesirable, cracking processes are of great commercial importance in increasing the yield of gasoline from a barrel of crude oil. See W. F. Rittman, C. B. Dutton, and E. W. Dean, Bulletin II 4 , Bureau of Mines, D. 5 ; 1916.
} 
work their way with the kerosene past the piston rings and down into the oil in the crank case. ${ }^{3}$ In special cases, when the piston rings are very tight and a very volatile fuel is used, there may be little or no dilution, and the oil increases in viscosity with use, as it does in a steam turbine.

Improvements in engine design have been proposed to prevent the kerosene from reaching the crank case or to distil it off continuously, ${ }^{4}$ but these devices are not in general use, and it may be assumed necessary to remove the kerosene from used automobile oils in order to bring them back to their original viscosity. It is safe to expect that improvements in engine design will not be perfected and adopted rapidly enough to counterbalance the steady decrease in the volatility of the fuel, ${ }^{5}$ and thus to prevent crank-case dilution.

\section{PRESENT METHODS OF RECLAIMING USED OILS.}

Several companies are now furnishing apparatus for reclaiming used oil either in batches or continuously. Considering first a process devised about I9I5, the reclaimer comprises a double steel shell, the annular space between the two shells serving as a water jacket. A continuous supply of hot water maintains a temperature of 140 to $160^{\circ} \mathrm{F}$. $\left(60.0\right.$ to $7 \mathrm{I.I}^{\circ} \mathrm{C}$.) in the oil under treatment. The inside shell is filled with equal parts of used oil and water. A pound of "special coagulant" for each 4 gallons of oil is dissolved in hot water and added to the oil, which is then thoroughly agitated for ro minutes by compressed air or otherwise. The clean oil is drawn off after the mixture has been allowed to settle for about ro hours.

It is stated that "the effect of this coagulant is not due to chemical action, but is purely mechanical, being based on the scientific principle of relative surface tensions of oil and water." It is difficult to judge the efficiency of this system, since, in the illustration given, the used oil taken from an oil engine had a higher flash point than the new oil, showing that there was no crank-case dilution from a volatile cracked product.

Another system which is extensively employed utilizes centrifugal force to remove impurities. The oil is first heated by blowing

\footnotetext{
${ }^{3}$ For the nature of carbon deposits see B. S. Circular No. 99, p. 4, 1920, and F. H. Garner, J. Inst. Petroleum Technologists, April, rg2I.

4 W. F. Parish, Scientific Lubrication, 1, p. 5; 192I. W. F. Parish, J. Soc. Automotive Engineers, 7, p. 23r; I92I. G. A. Kramer, J. Soc. Automotive Engineers, 6, p. I23; 1920.

${ }^{5}$ H. H. Hill and E. W. Dean, Bulletin I9r, Bureau of Mines, p. 100; 1920. N. A. C. Smith, Bureau of Mines, Reports of Investigations, Serial No. 2272, August, I92I.
} 
live steam into it, which removes the kerosene, and is then run through the centrifugal purifier, which removes all the water, metallic particles, and all of the carbon "except that which is in colloidal suspension." It is claimed that the colloidal carbon will not affect the lubricating qualities of the oil, but that it can be removed if desired by adding a "countercolloid" before centrifuging, a countercolloid evidently being a material to flocculate the colloids.

A continuous by-pass filtering system ${ }^{6}$ is coming into use for keeping steam-turbine oil in good condition and thus preventing the necessity of reclaiming oil in batches. The incoming oil is heated when necessary to lower its viscosity and thus reduce its ability to retain water and solid particles in suspension. Precipitation is induced by low velocities over shallow trays, and the oil finally passes through closely woven cloth by gravity. Table I gives some indication of the extent to which a continuous filtration system retards the increase in viscosity and in acidity during use. It is assumed that the acidity is referred to oleic acid in both cases.

TABLE 1.-Effect on Steam-Turbine Oils of Continuous Filtration.

\begin{tabular}{|c|c|c|c|c|}
\hline \multirow{2}{*}{ Test. } & \multicolumn{2}{|c|}{$\begin{array}{l}\text { National Electric } \\
\text { Light Association, } \\
\text { without filtration. }\end{array}$} & \multicolumn{2}{|c|}{$\begin{array}{l}\text { General Electric } \\
\text { Review, with fil- } \\
\text { tration. }\end{array}$} \\
\hline & $\begin{array}{l}\text { New } \\
\text { oil. }\end{array}$ & $\begin{array}{l}\text { After } 9 \\
\text { months. }\end{array}$ & $\begin{array}{l}\text { New } \\
\text { oil. }\end{array}$ & $\begin{array}{l}\text { After } 30 \\
\text { months' } \\
\text { use. }\end{array}$ \\
\hline 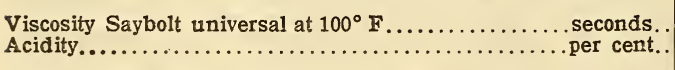 & $\begin{array}{c}148 \\
\ldots \ldots\end{array}$ & $\begin{array}{l}189 \\
.85\end{array}$ & 138 & $\begin{array}{l}139 \\
.25\end{array}$ \\
\hline
\end{tabular}

There is need of much more data to show how much of the difference in rate of deterioration of the oil indicated in Table $\mathrm{I}$ is due to filtration and how much to a difference in the quality of the oils when new. ${ }^{7}$ But apparently the acid tends to become segregated in the sludge, and the removal of sludge thus decreases the percentage of acidity, although the method of filtering is not a deoxidizing process, like filtering through fuller's earth in the refining of oil.

\footnotetext{
${ }^{6}$ Gen. Elec. Rev.; May, r921. Report of Prime Movers Committee, National Electric Light Association, p. 8; 1921.

${ }^{7}$ For changes in demulsibility with use see Winslow H. Herschel, B. S. Tech. Papers, No. 86, p. 36; 19r7. Demulsibility is a measure of the readiness of separation from an emulsion with water and varies inversely as the acidity.
} 
It is evident that the above-described method of filtering will not remove kerosene and can not be applied to the more complicated task of reclaiming motor oils. The following apparatus is used in reclaiming airplane motor oils and was used in the investigation to be described later:

The purifier consists essentially of two coaxial cylindrical shells of galvanized sheet steel, the space between being heated by steam. The apparatus is covered with a conical hood, which can be easily raised or lowered by means of a counterpoise. After Ioo gallons of dirty or used oil has been poured or pumped into the inner shell and the hood closed, steam at about 30 pounds gage pressure is admitted to the steam jacket until the thermometer shows a reading of from 190 to $212^{\circ} \mathrm{F}$. (87.8 to $100^{\circ} \mathrm{C}$.). Steam is now admitted to the inner shell, thus agitating the oil and at the same time raising its temperature to between 200 and $212^{\circ} \mathrm{F}$. $(93.3$ and $100^{\circ} \mathrm{C}$.). The necessary length of agitation depends upon the viscosity of the oil and the amount of dirt and kerosene it contains. The progress of driving off the kerosene is watched by testing samples of oil for flash point. When the flash point has reached approximately as high a value as that of the new oil it is known that the kerosene has nearly all been driven off. The maximum time generally found neceśsary for steaming is one hour.

According to the directions for operating the apparatus it may be necessary to finish the steam agitation of the oil at a higher pressure than 30 pounds. It is evidently impracticable, however, to drive off all the kerosene, since the end point for the highest grade of aviation gasoline ${ }^{8}$ is $165^{\circ} \mathrm{C}$. $\left(329^{\circ} \mathrm{F}\right.$.), a temperature which could only be reached with a steam pressure of 87 pounds gage pressure. It should also be observed that the flash point of a blended oil is higher than that of the constituent having the lower flash point, ${ }^{9}$ a fact which increases the difficulty of detecting the presence of small amounts of diluent.

After steam agitation has been completed from one-eighth to one-fourth pound of soda ash or sal soda for each gallon of oil to be treated should be thoroughly dissolved in sufficient water to obtain a saturated solution and the solution mixed with the oil. The function of the soda is to coagulate the carbon and other suspended impurities, the amount of soda required varying with the nature of the used oil, though an excess of soda does no harm.

8 Technical Paper No. 305, Bureau of Mines, p. 3; I922.

${ }^{\circ}$ H. C. Sherman, T. T. Gray, and H. A. Hammerschiag, J. Ind. and Eng. Chem., 1, p. I5; Ig09. 
After adding the soda solution the mixture is again agitated by steam for a minimum period of $\mathrm{I}_{5}$ minutes for light oils and longer for heavy oils. When using washing powders, which are said to give better results than sal soda, the steaming is the same as with sal soda, except that 5 to 15 minutes before the steaming is finished about I pound of washing powder to 75 gallons of dirty oil is added by sprinkling it upon the top of the oil. Some oils require as much as 4 pounds of washing powder.

The oil is now allowed to settle, ro hours being usually sufficient for light oils. During the settling period the steam jacket is kept at a temperature of $180^{\circ} \mathrm{F} .\left(82.2^{\circ} \mathrm{C}\right.$ ) , but with heavy oils it is well to keep the temperature at from 190 to $200^{\circ} \mathrm{F}$. (87.8 to $93.3^{\circ} \mathrm{C}$.) or as high as is possible without agitating the oil. Samples are taken from time to time and heated to $212^{\circ} \mathrm{F}$. $\left(100^{\circ} \mathrm{C}\right.$.). The presence of moisture is indicated by foaming, and particles of carbon still in the oil can be seen by diluting with gasoline.

When the settling is completed, there will be three layers in the inner compartment-water at the bottom, then sludge, and clean oil at the top. The clean oil is drawn off by admitting water to the bottom of the purifier. It is not desirable to try to get the last pint of clean oil off the sludge, because the surface of the sludge is irregular. The clean oil in being drawn off passes over a brightly polished overflow in a thin sheet, so that it can readily be seen whether the oil is bright and clear. As soon as particles of sludge appear on the overflow the oil should be diverted to the dirty oil tank.

\section{TESTS WITH MOTOR-OIL PURIFIER.}

The above-described apparatus was used through the courtesy of Lieut. Walter K. Burgess ${ }^{10}$ in an investigation of its efficiency in restoring to airplane oils their original properties, and Table 2 shows the results obtained. The oil is drained from the crank case of the airplanes after each trip, and trips vary in length, but the average length of time in use may be estimated as not over five hours. The sludge mentioned in the last column was taken from the middle layer of the purifier.

${ }^{10}$ Engineer officer, Bolling Field, Washington, D. C. 
TABLE 2.-Data on Results of Reclaiming Airplane Motor Oil.

\begin{tabular}{|c|c|c|c|c|}
\hline 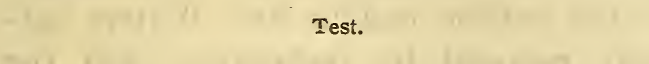 & New oil. & Used oil. & $\begin{array}{c}\text { Reclaimed } \\
\text { oil. }\end{array}$ & Sludge. \\
\hline 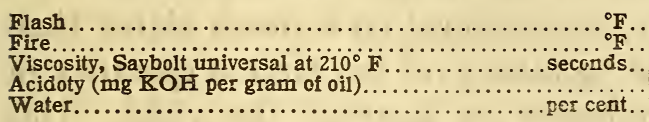 & $\begin{array}{l}518 \\
618 \\
130 \\
.056 \\
\text { None. }\end{array}$ & $\begin{array}{l}248 \\
536 \\
104 \\
\quad .112 \\
.05\end{array}$ & $\begin{array}{l}473 \\
563 \\
115 \\
\text { None. }\end{array}$ & $\begin{array}{l}0.222 \\
17.00\end{array}$ \\
\hline gravity, $\frac{\text { so }}{80} \ldots \ldots \ldots \ldots \ldots$ & $\begin{array}{l}.05 \\
.897\end{array}$ & $\begin{array}{l}2.00 \\
.896\end{array}$ & $\begin{array}{c}1.00 \\
.898\end{array}$ & $\begin{array}{r}15.00 \\
.903\end{array}$ \\
\hline 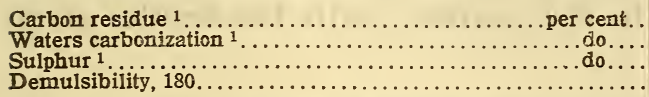 & $\begin{array}{c}2.35 \\
.20 \\
.09 \\
\text { Zero. }\end{array}$ & $\begin{array}{c}1.48 \\
\cdots \\
\text { Zis } \\
\text { Zero. }\end{array}$ & $\begin{array}{r}1.36 \\
.02 \\
(2)^{.15}\end{array}$ & $\begin{array}{c}1.35 \\
\cdots \text { iii } \\
\text { Zero. }\end{array}$ \\
\hline
\end{tabular}

1 The authors are indebted to C. E. Waters for the carbonization and sulphur tests and to N. Berryman, also of this bureau, for the carbon residue test.

${ }^{2}$ Would not emulsify.

All tests were made by the methods adopted by the Interdepartmental Petroleum Specifications Committee, ${ }^{11}$ with the following exceptions: Tests for demulsibility were run, except in regard to temperature, according to Technologic Papers of the Bureau of Standards, No. 86, and Waters carbonization according to Circular of the Bureau of Standards, No. 99, previously referred to. Sulphur was determined according to Technologic Papers of the Bureau of Standards, No. I77, page I9, I920.

The following method was used for determining acidity and is believed to give more accurate though higher results than the usual method. Forty grams of oil is accurately weighed and put into an Erlenmeyer flask, Ioo cc of 95 per cent ethyl alcohol is added, and the contents of the flask are thoroughly agitated; Ioo cc of distilled water is then added and the flasiz allowed to stand for 24 hours. The flask is heated to the boiling point, again agitated, and 50 cc of gasoline added. Using phenolphthalein as an indicator, the titration is made with $\mathrm{N} / \mathrm{IO} \mathrm{KOH}$ solution and the acidity calculated from the formula I cc $\mathrm{N} / \mathrm{IO}$ solution $=5.6 \mathrm{mg}$ $\mathrm{KOH}$ per gram of oil. A blank should be run, deducting the cubic centimeters required to neutralize the blank from the cubic centimeters required to neutralize the unknown sample.

It will be noted that the flash and fire points are higher for the reclaimed than for the used oil, but not as high as for the new oil, which is as would be expected. The viscosity of the reclaimed oil could be less readily foretold, because the kerosene which is not entirely eliminated tends to reduce the viscosity, and the oxidation of the oil tends to raise the viscosity. A longer period

11 Technical Paper 298, Bureau of Mines, 1922. $10388^{\circ}-22-2$ 
of use would be necessary to tell from the change in viscosity whether or not the oxidation was excessive.

Table 2 shows that both the carbon residue and Waters carbonization were considerably reduced by reclaiming. On the other hand, the sediment in the reclaimed oil is much higher than in the new oil, probably due to taking off too large a quantity of the reclaimed oil in an endeavor to increase the yield. This observation led to an examination of the amount of sediment in the oil at different depths in the purifier, with the results given in Table 3.

TABLE 3.-Examination of Samples Taken at Intervals During Drawing Off of Reclaimed Oil.

\begin{tabular}{|c|c|c|c|c|}
\hline Test. & $\begin{array}{c}\text { Sample } \\
\text { No. } 1 .\end{array}$ & $\begin{array}{l}\text { Sample } \\
\text { No.2. }\end{array}$ & $\begin{array}{l}\text { Sample } \\
\text { No. } 3 .\end{array}$ & $\begin{array}{l}\text { Sample } \\
\text { No. } 4 .\end{array}$ \\
\hline 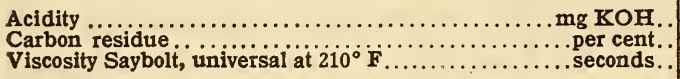 & $\begin{array}{l}0.11 \\
11.53\end{array}$ & $\begin{array}{r}0.11 \\
10{ }^{\prime} \cdots\end{array}$ & $\begin{aligned} 0.11 \\
11.56\end{aligned}$ & $\begin{array}{r}0.17 \\
3 i 0^{\cdots}\end{array}$ \\
\hline 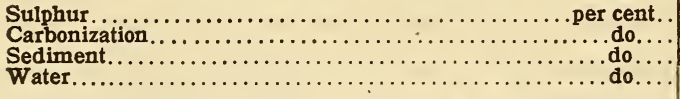 & $\begin{array}{r}.21 \\
.03 \\
.01 \\
\text { None. }\end{array}$ & $\begin{array}{r}.21 \\
\text { None. } \\
\text { Noi }\end{array}$ & $\begin{array}{r}.21 \\
.03 \\
.01 \\
\text { None. }\end{array}$ & $\begin{aligned} .21 \\
.0 .03 \\
\dot{20} .0\end{aligned}$ \\
\hline
\end{tabular}

The increase in values of the last column shows the danger in attempting to reclaim too high a percentage of the oil. It is much better to return the tailings to the used oil tank and treat this with the next batch, the high values showing that the sludge from the middle layer in the purifier was beginning to come off with the oil.

\section{ORGANIC ACIDITY.}

The oil of Table 2 was not used long enough to develop much acidity, and the acidity was reduced to that of the new oil by the process of reclaiming. With automobile oils which are used for longer periods of time and which develop a higher acidity there is more difficulty in reducing the acidity, and the question therefore arises whether this is necessary.

It had previously been supposed that all oils high in acidity would be low in demulsibility or resistance to emulsification, but this opinion was based entirely on tests made on eastern oils. When California oils were investigated, it was found quite possible to have an oil high in acidity and yet high in demulsibility. That is, of two oils of the same acidity, one from the East and one from California, the latter would have the higher demulsibility. 
This is shown by a comparison of data previously obtained from eastern oils ${ }^{12}$ with Table 4 for California oils.

TABLE 4.-Properties of Lubricating Oils from California Crude Oils.

\begin{tabular}{|c|c|c|c|c|}
\hline Oil No. & Acidity. & $\begin{array}{l}\text { Demulgi- } \\
\text { bility, } \\
\text { with } \\
\text { water, } \\
130^{\circ} \mathrm{F} \text {. }\end{array}$ & \begin{tabular}{|} 
Viscosity, \\
Saybolt \\
universal \\
at $100^{\circ} \mathrm{F}$
\end{tabular} & $\begin{array}{l}\text { Number } \\
\text { of drops. } 1\end{array}$ \\
\hline 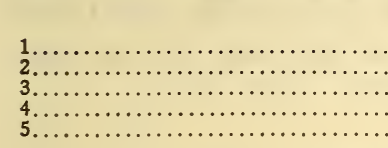 & $\begin{array}{r}\mathrm{Mg} \mathrm{KOH} \\
1.30 \\
1.05 \\
1.08 \\
1.34 \\
1.51\end{array}$ & $\begin{array}{r}240 \\
200 \\
600 \\
60 \\
228\end{array}$ & $\begin{array}{r}\text { Seconds. } \\
339 \\
380 \\
280 \\
280 \\
96\end{array}$ & $\begin{array}{l}41 \\
36 \\
35 \\
35 \\
24\end{array}$ \\
\hline 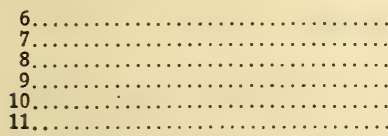 & $\begin{array}{l}0.62 \\
1.09 \\
1.20 \\
0.76 \\
0.67 \\
1.15\end{array}$ & $\begin{array}{r}120 \\
90 \\
168 \\
104 \\
163 \\
120\end{array}$ & $\begin{array}{l}465 \\
335 \\
209 \\
470 \\
195 \\
392\end{array}$ & $\begin{array}{l}35 \\
37 \\
41 \\
39 \\
43 \\
45\end{array}$ \\
\hline
\end{tabular}

1 Obtained with a Gardner and Holdt interfacial tension apparatus. The interfacial tension is inversely proportional to the number of drops in a given volume, as explained later.

It should not be assumed that the acidity of all California lubricating oils would average as high as in Table 4, the oils for which were selected to show the relation between acidity and demulsibility, yet there is no doubt that the average California oil is much higher in acidity than the average eastern oil. The question to be decided is whether the California oils contain the same or an equally undesirable acid as the eastern oils.

In all cases the demulsibility when run with normal $\mathrm{NaOH}$ solution in place of distilled water was zero, and the corrosion test gave a negative result. It was noted in making the demulsibility tests with water that in many cases the oil separated quickly but incompletely from an emulsion, and this brought to mind the contention of Conradson ${ }^{13}$ that completeness of separation is an important property of the oil which ought to be tested by determining the percentage of water in the upper layer which separates out from an emulsion. This idea is carried out in the Government methods for testing petroleum products. ${ }^{14}$

It is desirable that oils should have high demulsibility or separate readily from water, both in order that they may not cause trouble by emulsifying in use or in being reclaimed. But if the oil is noncorrosive and it separates rapidly and completely enough from an emulsion, then the desirability or undesirability of high acidity must be based on other grounds.

12 B. S. Tech. Papers, No. 86, p. $28 ; 1917$.

13 P. H. Conradson, Proc. A. S. T. M., 16, part 2, p. 273; 1916.

14 Method 300.4 ('Technical Paper 298, p. 40), for obtaining water by centrifuge, is for use in this connection. 
In some English experiments ${ }^{15}$ petroleum acid was produced by blowing air through neutral filtered spindle oil heated to a high temperature $\left(360\right.$ to $400^{\circ} \mathrm{F}$., I82 to $204^{\circ} \mathrm{C}$.) to accelerate the oxidation. To the oil thus prepared was added the prescribed amount of oildag, and it was found that the presence of o.I per cent of petroleum acid caused complete precipitation of the graphite in five hours. More important considerations are the possible reduction in coefficient of friction due to the use of an oil of high acidity or, on the other hand, an increase in the rate of oxidation in use.

\section{INTERFACIAL TENSION.}

The question of organic acidity has been in a chaotic condition ever since Wells and Southcombe ${ }^{16}$ found that certain organic acids added to a petroleum oil in minute quantities had the effect of considerably reducing the coefficient of friction. They used organic acids derived from fatty oils, and they emphasize the point that all organic acids do not have the effect of decreasing the interfacial tension between the lubricant and the bearing metal and thus decreasing the coefficient of friction.

It is interesting to observe that while the use of compounded oils in steam-engine cylinders is a well-established practice, compounded oils are practically never used in internal-combustion engines in the United States, although their use in such engines appears to be well established in England. ${ }^{17}$ It can not be assumed without further evidence that the petroleum acids will be as advantageous as the organic acids derived from fatty oils, the term "petroleum acids" being used for the unidentified acids to be found in petroleum oils which are free from fatty and mineral acids. It is possible that if a certain amount of acidity is desirable a compromise would have to be made between too much acid which would be an indication of a "gummy" oil and too little acid which would prevent the attainment of the lowest practicable coefficient of friction.

15 Bull. No. 4, Dept. of Scientific and Industrial Research, p. 20; 1920.

${ }_{16}$ H. M. Wells and J. E. Southcombe, J. Soc. Chem. Ind., p. 5 I T; I920. Winslow H. Fierschel, J. S. A. E., 10, pp. 3I, 369; I922.

17 Geo. H. Hurst, Lubricating Oils, Fats, and Greases, p. 323; r9r1. 
Pending the construction of a suitable oil-friction testing machine the apparatus of Donnan, ${ }^{18}$ as used by Wells and Southcombe, was used to determine the effect of variations in organic acidity upon the interfacial tension. With this apparatus drops of oil are released under water, and the relative interfacial tension of different oils is indicated by the size or number of drops in a given volume. It was found that the apparatus gave somewhat discordant results. This was attributed to the impossibility of keeping the end of the capillary absolutely clean, and somewhat better results were obtained after the end had been tapered to a. thin edge.

Since making the required samples by isolating the acid and adding it to a neutral oil in various proportions would have been, if possible, a prolonged operation, the samples were prepared by mixing in various proportions an oil of high acidity with one of low acidity. It was at first assumed that a used oil would be suitable for the oil of high acidity, but one which was discarded as unfit for further use in an engine gave an acidity of only 0.20 $\mathrm{mg} \mathrm{KOH}$. This showed 62 drops in the interfacial tension apparatus. The oils used in blending were, (A) a class $B$ oil purchased on Government specifications, (B) an eastern oil of unusually high acidity which had emulsified when used in an automobile, and (C) lard oil several years old, the same sample as used by Bingham. ${ }^{19}$

The viscosities of blends of oils $A$ and $B$ did not vary more than the experimental error, the corrosion test showed negative results, and the demulsibility was zero for acidities of $0.33 \mathrm{mg} \mathrm{KOH}$ and over. With blends of oils A and C the viscosity, Saybolt Universal at $25^{\circ} \mathrm{C}$. $\left(77^{\circ} \mathrm{F}\right.$.), varied from I, I34 seconds for oil A to $33^{8}$ for oil $\mathrm{C}$. The demulsibility was reduced to zero by the addition of I2.5 per cent of the lard oil. A compound with 37.5 per cent of lard oil with an acidity of $2.69 \mathrm{mg} \mathrm{KOH}$ showed slight corrosion, and higher acidities showed much greater corrosion. The comparison of acidities and number of drops obtained with the interfacial tension apparatus is shown in Table 5 .

\footnotetext{
18 F. G. Donnan. Zs. f. Physik. Chem., 31. The apparatus as made in the United States is illustrated in paper by H. A. Gardner and P. C. Holdt, Circular I24, Paint Manufacturers' Assoc. of the U. S., p. 6; May. I92I.

19 E. C. Bingham, B. S. Tech. Papers, No. 204, p. 59; 1922.
} 
TABLE 5.-Interfacial Tension of Oils of Various Acidities. BLENDS OF OILS A AND B.

\begin{tabular}{|c|c|c|c|c|c|}
\hline Oil $\mathbf{A}$ (per cent). & $\begin{array}{l}\text { Acidity } \\
\text { (mg } \\
\mathrm{KOH}) .\end{array}$ & $\begin{array}{l}\text { Number } \\
\text { of drops. }\end{array}$ & Oil A (per cent). & $\begin{array}{l}\text { Acidity } \\
\text { (mg } \\
\text { KOH). }\end{array}$ & $\begin{array}{l}\text { Number } \\
\text { of drops. }\end{array}$ \\
\hline $\begin{array}{r}100 \\
95 \\
90 \\
85 \\
85 \\
80 \ldots \ldots\end{array}$ & $\begin{array}{l}0.04 \\
.08 \\
.12 \\
.17 \\
.20\end{array}$ & $\begin{array}{l}66 \\
70 \\
77 \\
80 \\
82\end{array}$ & $\begin{array}{l}50 \\
45 \\
40 \\
35 \\
35 \cdots \cdots \\
30 \ldots \cdots \cdots \cdots\end{array}$ & $\begin{array}{l}0.45 \\
.48 \\
.52 \\
.56 \\
.59\end{array}$ & $\begin{array}{l}73 \\
73 \\
75 \\
76 \\
76\end{array}$ \\
\hline 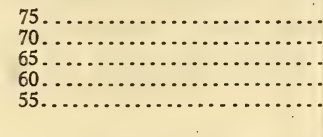 & $\begin{array}{l}.22 \\
.28 \\
.32 \\
.33 \\
.40\end{array}$ & $\begin{array}{l}85 \\
85 \\
76 \\
73 \\
71\end{array}$ & $\begin{array}{r}25 \\
20 \\
15 \\
10 \\
5 \\
5 \\
0\end{array}$ & $\begin{array}{l}.61 \\
.68 \\
.72 \\
.76 \\
.80 \\
.84\end{array}$ & $\begin{array}{l}77 \\
75 \\
76 \\
70 \\
67 \\
57\end{array}$ \\
\hline
\end{tabular}

OIL A COMPOUNDED WITH OIL C.

\begin{tabular}{|c|c|c|c|c|c|}
\hline $\begin{array}{r}100.0 \\
87.5 \\
75.0 \\
62.5 \\
50.0 \ldots \ldots\end{array}$ & $\begin{array}{l}0.04 \\
1.12 \\
1.85 \\
2.69 \\
3.66\end{array}$ & $\begin{array}{r}66 \\
110 \\
113 \\
111 \\
95\end{array}$ & 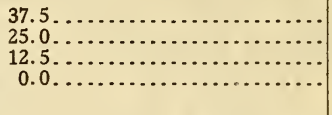 & $\begin{array}{l}4.59 \\
5.47 \\
6.38 \\
7.28\end{array}$ & $\begin{array}{r}95 \\
86 \\
95 \\
102\end{array}$ \\
\hline
\end{tabular}

Table 5 shows a decrease in interfacial tension due to the addition of lard oil, but results with blends of oils $\mathrm{A}$ and $\mathrm{B}$ are inconclusive. Apparently either the apparatus is not accurate enough to detect the slight differences in acidity between different samples or the petroleum acids in different oils were not the same, and the effect of blending different unknown acids in varying proportions can not be foretold.

\section{REFINING PROCESSES.}

The acidity of a lubricating oil may be due to acidity of the crude oil or may be developed during the process of refining. Acidities of crude oil are not ordinarily reported, but they are apparently relatively low. Three samples selected at random showed acidities of $0.1 \mathrm{I}, 0.06$ and $0.06 \mathrm{mg} \mathrm{KOH}$ for Texas, Midcontinent, and Pennsylvania crudes, respectively. If there was no reduction of acidity due to the refining, the acidity of a lubricating oil would be much greater than that of the original crude on account of the concentration of the acid of the crude in the much smaller volume of the lubricant.

The process of refining must necessarily vary with the nature of the crude oil, but it consists in general of distilling off the lighter portion from which fuels are made and continuing the process to obtain the lubricating oils distillate. This distillate is separated by a second distillation into fractions of different 
viscosities, and the fractions are treated with sulphuric acid and neutralized with caustic soda, the soda apparently acting to precipitate impurities as well as to neutralize the acid left in the oil. Filtration through fuller's earth serves a similar purpose to the acid treatment. In the case of oils containing much oxygen a preliminary treatment with soda before distillation may be beneficial, ${ }^{20}$ and where there is considerable sulphur in the crude it may be necessary to redistil after acid treatment and neutralization. The most probable action of this redistillation is to break up the compounds formed by the action of the sulphuric acid on some of the constituents of the oil and allow the sulphur dioxide to escape.

A certain amount of cracking as well as oxidation is unavoidable in refining, although ordinarily steam is introduced to prevent the cracking as much as possible, and in some cases a vacuum is employed for the same purpose. It is reasonable to suppose that an oil which will oxidize or disintegrate more readily than another in refining will also deteriorate more rapidly in use.

Since acidity is developed during oxidation, an acidity test may be used as an indication of the resistance of the oil to oxidation or of the adequacy of the acid treatment or filtration to reduce the acidity thus formed or that originally present in the crude. It might appear at first sight that the acidity test is of small value in the case of an automobile oil, since the acidity is increased (or the demulsibility reduced) after a very short time in use, but this reasoning is not valid. The difference in chemical stability of the original oils still remains. If all of a series of oils will emulsify, it proves that the acidity is at least equal to the minimum value required to cause emulsification, but not that all of the series are of equal acidity or that all will deteriorate with equal rapidity.

Adequate filtration or great care in the removal of the sludge formed in acid treatment will produce an oil which will be satisfactory as regards acidity or demulsibility. Only o.I per cent of the acid sludge left in the oil would reduce the demulsibility from $I, 200$ to 300 . Acid treatment is also said to reduce the carbon residue, a test which may be used to detect oils made by blending light oils with unfiltered cylinder stock.

It is apparently more difficult to reduce the carbonization value, which in general is higher for naphthene base oils and for

${ }^{20}$ B. Redwood, A Treatise on petroleum, 2, p. 523; 1922. 
oils of low viscosity, ${ }^{21}$ while the carbon residue is higher for paraffin base crudes and for oils of high viscosity. Whether or not the carbonization value can be controlled except by choice of crude has no bearing upon the desirability of oils showing a low carbonization value or a high resistance to oxidation.

\section{THE CAUSE OF SLUDGE FORMATION.}

Failure of lubrication is due primarily to one of two causes. Either the lubricant becomes so low in viscosity from dilution or from excessively high temperatures that it can not prevent metallic contract, or it may fail to reach the rubbing surfaces because it is too viscous or full of sediment or sludge to pass through the oil passages. The choice of an oil of suitable viscosity when new and a sufficiently frequent removal of the diluent will guard against the first form of failure. An emulsifying oil may cause failure from the second cause, even if sludge and sediment are not formed, because emulsions are more viscous than the oils from which they are made.

It is not certain whether sludge should be regarded as an emulsion or as an oxidation product, since the conditions are favorable for the formation of both. The metallic particles from the bearings are in a finely divided state and suited to cause catalytic oxidation of the oils. ${ }^{22}$ Waters has also found that organic sulphur compounds present in the crude oil and not removed by refining will increase the rate of oxidation, although they can not be detected by the corrosion test. Elsewhere he remarks: ${ }^{23}$

Transformer oils are regarded as undesirable if they contain more than a very small portion of sulphur, because this element is believed to attack the wires and also to increase the tendency to form sludge. ***. No oil which contains much sulphur will have a low carbonization value.

These quotations suggest the use of the tests for sulphur or Waters carbonization to select an oil which would not be apt to form sludge or to determine whether or not reclaimed oils had been restored to as good a quality as when new. While the test for acidity is simpler, it is doubtful whether it would serve the same purpose, since there does not appear always to be a marked correlation between acidity and carbonization, ${ }^{24}$ though Waters ${ }^{25}$

21 W. F. Parish, J. Am. Soc. Nav. Eng., 32, p. 55; 1920.

${ }_{22}$ C. E. Waters, J. Ind. and Eng. Chem., 13, p. 90r, I92 I, and 14, p. 725; r922.

23 C. E. Waters, B. S. Tech. Papers, No. 177 , p. 8; 1920.

21 B. S. Tech. Papers, No. 86, p. 28.

${ }^{25}$ C. E. Waters, B. S. Tech. Papers, No. 73; 1916. 
found that acidity and carbonization both increased when oils were exposed to sunlight.

A sludge is unlike an emulsion in that it does not form suddenly but only after the oil has been subjected to prolonged use, and the formation of sludge would therefore appear to be due to changes in the oil which gradually develop. The changes which are known to occur are: (a) Accumulation of metallic particles, $(b)$ accumulation of dust, $(c)$ in the case of internal-combustion engines the accumulation of "carbon" from the cylinders, and $(d)$ oxidation of the oil, accompanied by an increase in acidity and the formation of oxidation products of a tarry or asphaltic nature.

Of the four possible causes of sludge formation $(d)$ is the only one which depends upon the lubricant. It is not certain just how oxidation acts to cause sludge or whether or not sulphur exerts an influence. There appear to be two general possibilities. First, the nucleus of a particle may be a drop of water which is surrounded by colloidal carbon, the oxidation product serving as a binder to make the carbon into a continuous coating, so that the drops are prevented from coalescing. Again, the nucleus may be a particle of carbon or road dust, to which the oxidation products adhere. When the sticky particles coalesce into sufficiently large masses to be visible or to be precipitated, the material is called sludge. Examination with a microscope seemed to indicate from the lack of angularity of the nucleus that it was a drop of water; and that therefore sludge formation was a case of permanent emulsion due to colloids or finely divided solids. ${ }^{26}$ However this may be, either supposition in regard to the formation of sludge would point toward the necessity of removing carbon, road dust, oxidation products, and a possible need of reducing the acidity and sulphur content.

Table 6 shows results of the examination of several sludges. The material was removed from the turbine oil by a centrifuge, it was precipitated from the crank-case oil by gravity, and the sludge from the transformer oil was a fairly solid mass that adhered to the core of the transformer. The last column gives data on the oil from which the crank-case sludge was precipitated.

\footnotetext{
${ }^{26}$ See T. R. Briggs, J. Ind. and Eng. Chem., 13, p. I008; I92I.
} 
TABLE 6.-Analysis of Sludges.

\begin{tabular}{|c|c|c|c|c|c|}
\hline & Material. & $\begin{array}{l}\text { Turbine } \\
\text { sludge. }\end{array}$ & $\begin{array}{l}\text { Trans- } \\
\text { former } \\
\text { sludge. }\end{array}$ & $\begin{array}{c}\text { Crank- } \\
\text { case. } \\
\text { sludge. }\end{array}$ & Used oil. \\
\hline $\begin{array}{l}\text { Oil.......... } \\
\text { Tarry matter } \\
\text { Volatile...... } \\
\text { Carbon....... } \\
\text { Ash......... }\end{array}$ & & $\begin{array}{r}\text { Per cent. } \\
48.90 \\
14.22 \\
11.54 \\
6.56 \\
18.64\end{array}$ & $\begin{array}{r}\text { Per cent. } \\
65.10 \\
4.20 \\
4.56 \\
25.44 \\
.48\end{array}$ & $\begin{array}{r}\text { Per cent. } \\
31.54 \\
.46 \\
62.68 \\
3.98 \\
1.12\end{array}$ & $\begin{array}{r}\text { Per cent. } \\
74.09 \\
25.06 \\
.40 \\
.24 \\
.16\end{array}$ \\
\hline Total. & 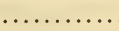 & 99.86 & 99.78 & 99.78 & 99.95 \\
\hline
\end{tabular}

ANALYSIS OF ASH.

\begin{tabular}{|c|c|c|c|c|}
\hline 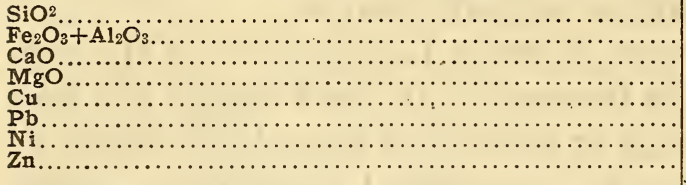 & $\begin{array}{r}42.22 \\
35.27 \\
\text { Trace. } \\
\text { Trace. } \\
6.83 \\
2.46 \\
6.45\end{array}$ & $\begin{array}{r}12.08 \\
37.14 \\
9.60 \\
\text { Trace. } \\
33.92 \\
5.42 \\
\text { Trace. } \\
\text {. }\end{array}$ & $\begin{array}{r}9.54 \\
82.46 \\
2.31 \\
\text { Trace. } \\
2.71 \\
1.05 \\
\text { Trace. } \\
\end{array}$ & 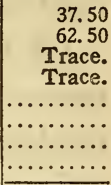 \\
\hline 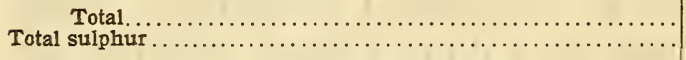 & $\begin{array}{r}93.23 \\
.33\end{array}$ & $\begin{array}{r}98.16 \\
.21\end{array}$ & $\begin{array}{r}98.07 \\
.77\end{array}$ & $\begin{array}{r}100.00 \\
.56\end{array}$ \\
\hline
\end{tabular}

The amount of silica in the steam-turbine oil sludge is surprising. As the turbine had been in use for several years, it is hard to believe that the silica came from the core sand of the turbine casing, and it is also difficult to believe that it came from the dust in the atmosphere of a power station. The transformer oil sludge is due to different causes ${ }^{27}$ and is presented only for comparison. The amount of copper in the ash is noteworthy.

\section{CONCLUSIONS.}

I. Used oils should be judged by the same tests as are applied to new oils and will be equally serviceable.

2. The present methods of reclaiming oil are successful as far as the generally recognized tests are concerned, and improvements are limited by lack of knowledge concerning what additional tests are needed to make sure that oils, whether new or reclaimed, possess those properties which make them suitable when new and durable in use.

3. Further investigation is needed concerning the value of the tests for acidity, sulphur, and resistance to oxidation.

WASHINGTON, July 5, 1922.

${ }^{27}$ See paper by C. J. Rodman presented before the American Electrochemical Society, p. I05; I921. 